\section{Suppression of the Bitterness of Enteral Nutrients Using Increased Particle Sizes of Branched-Chain Amino Acids (BCAAs) and Various Flavours: a Taste Sensor Study}

\author{
Yohko Miyanaga, ${ }^{a}$ Junji Mukai, ${ }^{a}$ Tadashi Mukai, ${ }^{b}$ \\ Masaaki Odomi, ${ }^{b}$ and Takahiro UchidA ${ }^{*}, a$ \\ ${ }^{a}$ School of Pharmaceutical Sciences, Mukogawa Women's \\ University; 11-68 Koshien 9-Bancho, Nishinomiya 663-8179, \\ Japan: and ${ }^{b}$ Formulation Research Institute, Otsuka \\ Pharmaceutical Co., Ltd.; 224-18 Ebisuno, Hiraishi Kawauchi-cho, \\ Tokushima 771-0182, Japan. \\ Received January 6, 2004; accepted March 9, 2004; published \\ online March 9, 2004
}

An improved formulation of the enteral nutrient Aminoleban $^{\circledR}$ EN (Otsuka Pharmaceutical Co., Ltd., Tokyo, Japan), has been commercially available since Spring 2004. Like the previous formulation, the improved product contains branched-chain amino acids (BCAAs) L-isoleucine (L-Ile), Lleucine (L-Leu), and $\mathrm{L}$-valine ( $\mathrm{L}-\mathrm{Val}$ ), but the average particle size of these amino acids has been increased to 180 to $250 \mu \mathrm{m}$ in the improved formulation, compared with 40 to $90 \mu \mathrm{m}$ in the old product. The improved formulation has a significantly lower bitterness intensity score than the older formulation, as evaluated both in human gustatory tests and using the artificial taste sensor. We propose that this improved taste masking is due to the larger particle size of the BCAA crystals, due to which their release rates are reduced. The addition of improved flavours has also helped to reduce the bitterness of the improved Aminoleban ${ }^{\circledR}$ EN formulation significantly. Analysis of the taste sensor data suggests that the sourness and sweetness of the added flavours were critical in diminishing the bitterness of Aminoleban ${ }^{\circledR}$ EN.

Key words enteral nutrient; taste sensor; bitterness; sweetness; sourness; flavour

Aminoleban ${ }^{\circledR}$ EN (Otsuka Pharmaceutical Co., Ltd., Tokyo, Japan), is a typical enteral nutrient on the Japanese market and is taken mainly by patients with severe hepatic disease. Such patients usually drink $50 \mathrm{~g}$ Aminoleban ${ }^{\circledR}$ EN, dissolved in $180 \mathrm{ml}$ water and mixed with $6 \mathrm{~g}$ flavour, three times a day, as instructed in the product's package insert. Aminoleban ${ }^{\circledR}$ EN contains a mixture of the branched-chain amino acids (BCAAs) L-isoleucine (Ile), L-leucine (Leu), and L-valine (Val), which are added in order to improve Fischer's rate, ${ }^{1,2)}$ but which have an extremely bitter taste. Patients must often take these enteral nutrients for long periods, and their bitterness is not only unpleasant but may also cause decreased compliance and/or intake. Bitterness masking is therefore extremely important for such diets.

In the present study, we investigated the taste of a new, improved, formulation of Aminoleban ${ }^{\circledR}$ EN which has been commercially available since Spring 2004. This improved formulation contains larger particle sizes of BCAAs than the old formulation (mean diameter 180 to $250 \mu \mathrm{m}$ compared with 40 to $90 \mu \mathrm{m}$ in the old formulation). In addition, the flavours with which the enteral nutrient is usually taken have also been improved. The goal of the present study was to compare the bitterness of the old and improved Aminoleban ${ }^{\circledR}$ EN formulations in human gustatory sensation tests and using the artificial taste sensor.

The gustatory sensation tests were conducted according to a previously described method ${ }^{3-5)}$ and were performed with nine human volunteers. The sample size was $2.5 \mathrm{ml}$ and all samples were kept in the mouth for $10 \mathrm{~s}$. After tasting, subjects gargled well before tasting the next sample.

As various concentration of four basic taste standards, quinine solutions $(0.003,0.012,0.031,0.078$, and $0.201 \mathrm{~mm})$ for bitterness, sucrose solutions $(29,87,187,409$, and $994 \mathrm{~mm})$ for sweetness, tartaric acid solutions $(0.17,0.60,1.73,4.66$, and $11.99 \mathrm{~mm}$ ) for sourness, and sodium chloride solutions $(21,51,130,274$, and $616 \mathrm{~mm})$ for saltiness which corresponded to scores of $0-4$ in the gustatory sensation tests, were used.

After tasting the standard solutions, the volunteers were asked to taste samples of the old and improved Aminoleban ${ }^{\circledR}$ EN without any added flavour, and improved Aminoleban ${ }^{\circledR}$ EN in the presence of each of the five new or improved flavours (apple, pineapple, fruit, coffee and powdered green tea). The samples consisted of $2.5 \mathrm{ml}$ of a solution of $50 \mathrm{~g}$ Aminoleban ${ }^{\circledR}$ EN dissolved in $180 \mathrm{ml}$ water, to which $6 \mathrm{~g}$ of each of the five flavours was added where relevant. The volunteers were asked to score the samples in terms of their four basic taste intensities and also to give an overall palatability score, defined as follows: 0 , extremely difficult to drink; 1 , slightly difficult to drink; 2 , neither easy nor difficult to drink; 3 , quite easy to drink; 4 , extremely easy to drink.

Release characteristics of BCAAs from improved and old Aminoleban ${ }^{\circledR}$ EN were performed as follows: $50 \mathrm{~g}$ of two products were well suspended in $180 \mathrm{ml}$ of purifies water and stored at $25^{\circ} \mathrm{C}$ or $4^{\circ} \mathrm{C}$. The samples were withdrawn at 0,4 , 8 and $24 \mathrm{~h}$. Those samples were immediately filtered with millipore-filter $(0.45 \mu \mathrm{m})$ and $10 \mu \mathrm{l}$ of the diluted sample was injected into amino acid analyzer (HITACHI L-8500, Hitachi Co. Ltd., Tokyo, Japan).

The taste sensor system, SA402B of Intelligent Sensor Technology Co., Ltd., Atsugi, Japan, was used to measure the electric potential of the enteral nutrient. Measurements using the artificial taste sensor were performed on $50 \mathrm{~g}$ Aminoleban ${ }^{\circledR} \mathrm{EN}$ dissolved in $180 \mathrm{ml}$ of water, with or without the addition of $6 \mathrm{~g}$ of flavour. The diluent for sample preparations in the taste sensor tests was $10 \mathrm{~mm} \mathrm{KCl}$ solution, which has no taste but which improves conductibility. The taste sensor system and the lipid components of the sensor used in the present study are essentially same as those described in a previous paper.6) However, in the present study, a different sensor was used, composed of dioctyl phenyl-phosphonate, phosphoric acid di- $n$-hexadecyl ester and tetradodecylammoniumbromide. This sensor is more sensitive to sweetness than the sensor used in our previous paper. Relative sensor output ( $R$ values) and the change of membrane potential caused by adsorption (CPA) were used to predict the bitterness of the enteral nutrient solutions. The correlation between the bitterness intensity of various enteral nutrients as evaluated by human gustatory sensation tests and that predicted by the artificial taste sensor was analysed using regression analysis and the $F$ test. $p$ values of $p<0.10$ or $p<0.005$ were accepted as significant. S-PLUS 2000J (Mathematical Systems, Inc., 
Table 1. The Four Basic Taste Intensity Scores and the Overall Palatability Score for the Seven Samples Used in the Human Gustatory Sensation Tests (Old and Improved Aminoleban ${ }^{\circledR}$ EN without Any Added Flavour, and Improved Aminoleban ${ }^{\circledR}$ EN in Presence of Each of the Five Flavours)

\begin{tabular}{|c|c|c|c|c|c|}
\hline & $\begin{array}{l}\text { Overal palatability } \\
\text { score }\end{array}$ & Sweetness & Sourness & Saltness & Biterness \\
\hline Old & $0.3 \pm 0.2$ & $0.4 \pm 0.2$ & $0.4 \pm 0.2$ & $0.7 \pm 0.2$ & $2.6 \pm 0.2$ \\
\hline Improved & $0.9 \pm 0.3$ & $0.8 \pm 0.2$ & $0.2 \pm 0.1$ & $0.4 \pm 0.2$ & $1.3 \pm 0.2 * *$ \\
\hline Improved + apple & $1.6 \pm 0.4$ & $1.3 \pm 0.2 *$ & $2.3 \pm 0.2 * * *$ & $0.2 \pm 0.1$ & $0.7 \pm 0.2^{* * *, \#}$ \\
\hline Improved + pineapple & $2.4 \pm 0.4$ & $1.4 \pm 0.2 * *, \#$ & $2.4 \pm 0.2 * * *, \ldots \#$ & $0.3 \pm 0.2$ & $0.4 \pm 0.2 * * *$ \#\# \\
\hline Improved + fruit & $2.6 \pm 0.3$ & $1.9 \pm 0.3 * *$ & $2.4 \pm 0.2 * * * \ldots \#$ & $0.3 \pm 0.2$ & $0.3 \pm 0.2^{* * *}$,\#\# \\
\hline Improved + coffee & $2.1 \pm 0.4$ & $0.9 \pm 0.3$ & $0.2 \pm 0.1$ & $0.1 \pm 0.1$ & $1.2 \pm 0.2 * * *$ \\
\hline Improved + green tea & $0.7 \pm 0.4$ & $1.1 \pm 0.3$ & $0.4 \pm 0.2$ & $0.4 \pm 0.2$ & $1.3 \pm 0.2 * *$ \\
\hline Correlation with overall palatability score & & 0.777 & 0.679 & -0.724 & -0.839 \\
\hline
\end{tabular}

Each value represents the mean \pm S.E. $(n=9)$. Significantly different from the old Aminoleban ${ }^{\circledR}$ EN, $* p<0.010, * * p<0.005, * * * p<0.001$. Significantly different from the improved Aminoleban ${ }^{\circledR} \mathrm{EN},{ }^{\#} p<0.050, \# p<0.010,{ }^{\# \#} p<0.005$.

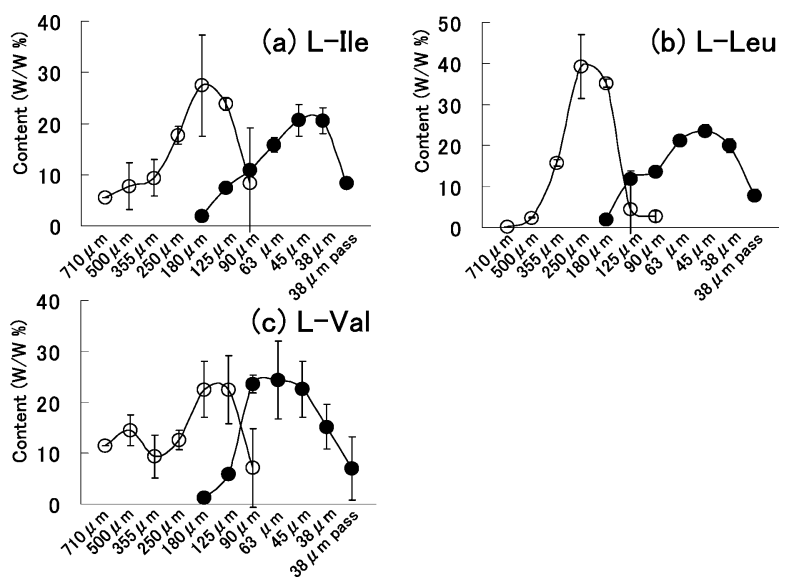

Fig. 1. The Particle Size Distribution of Isoleucine (a), Leucine (b), and Valine (c) Included in Old $(\bullet)$ and Improved $(\bigcirc)$ Formulations of Aminoleban ${ }^{\circledR} \mathrm{EN}$

Tokyo, Japan) was used for regression analysis.

The difference among taste intensity scores for samples was analyzed using the Mann Whitney $U$-test, non-parametric method. The actual analysis was performed using software located in the website at http://aoki2.si.gunmau.ac.jp/lecture/stats-by-excel/vba/html/two_sample.html.

Table 1 shows the overall palatability score and the four basic taste intensity scores for the seven samples used in the human gustatory sensation tests. There was an inverse relation between the bitterness intensity score and the overall palatability score $(-0.839)$ for the old and improved Aminoleban ${ }^{\circledR}$ EN products. The bitterness intensity score of the old Aminoleban ${ }^{\circledR}$ EN was significantly reduced in the improved formulation (from 2.6 to 1.3). When we express this reduction as equivalent quinine concentration ratios as described in the previous article, ${ }^{7)}$ the reduction ratio was calculated to be $28 \%$ since quinine concentration corresponding to 2.6 and 1.3 were $0.050 \mathrm{~mm}$ and $0.014 \mathrm{~mm}$ respectively. It can therefore be concluded that the measures taken to reduce the bitterness of the formulation have been effective in increasing the overall palatability of the diet.

Figure 1 shows the particle size distributions for isoleucine (a), leucine (b), and valine (c) in old and improved Aminoleban ${ }^{\circledR}$ EN product. The data was represented as the average values of three batches as determined by particle size distribution estimation by analytical sieving. The mean particle
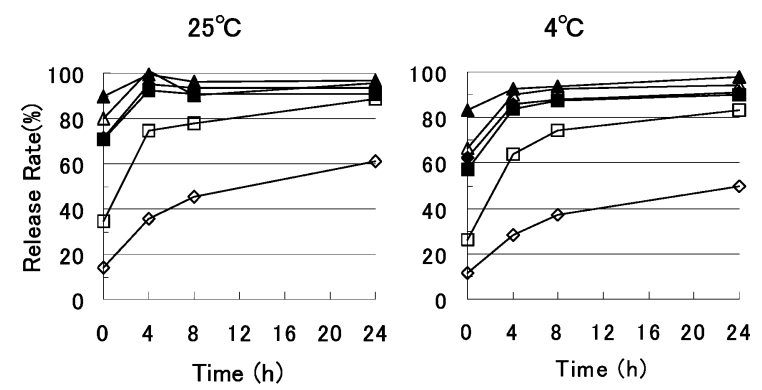

Fig. 2. The Release Characteristics of Each BCAA from Old and Improved Aminoleban ${ }^{\circledR} \mathrm{EN}$ at $25^{\circ} \mathrm{C}$ (Left Fig.) and $4{ }^{\circ} \mathrm{C}$ (Right Fig.)

$\square$, improved L-Ile; $\diamond$, improved L-Leu; $\triangle$, improved L-Val; $\mathbf{\square}$, old L-Ile; $\bullet$, old LLeu; $\boldsymbol{\Lambda}$, old L-Val.
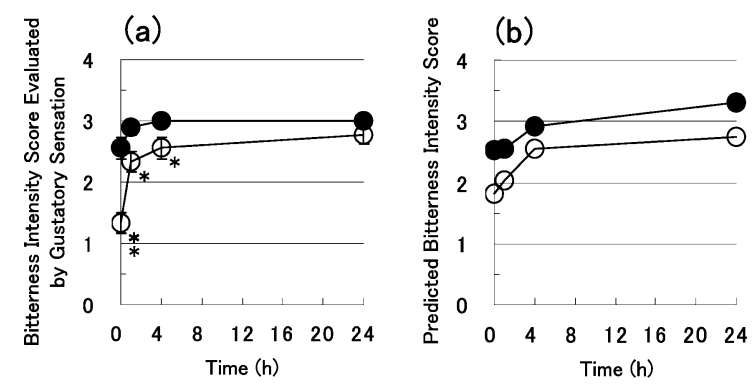

Fig. 3. The Obtained (a) and Predicted (b) Bitterness Intensity Scores Evaluated in Human Gustatory or Taste Sensor Tests for Old $(-)$ and Improved $(\bigcirc)$ Formulations of Aminoleban ${ }^{\circledR}$ EN Dissolved in $180 \mathrm{ml}$ of Water Immediately or 1, 4 and $24 \mathrm{~h}$ after Sample Preparation

Error bars represent the mean plus or minus standard error $(n=9) . * p<0.05$, ** $p<0.005$ compared with old Aminoleban ${ }^{\circledR}$ EN.

sizes are about $180-250 \mu \mathrm{m}$ in the improved Aminoleban ${ }^{\circledR}$ EN product, compared with about $40-90 \mu \mathrm{m}$ in the old product.

Figure 2 shows the release characteristics of each BCAA from old and improved Aminoleban ${ }^{\circledR}$ EN using amino acid analyzer. The release rate of BCAA from improved product was dramatically reduced compared with that of old product at $25^{\circ} \mathrm{C}$ (left fig.) and $4{ }^{\circ} \mathrm{C}$ (right fig.). In a pilot study on the bitterness of Aminoleban ${ }^{\circledR}$ EN we showed that the bitterness of the product was mainly due to the BCAAs. A critical factor in this bitterness appears to be the particle size of the BCAAs, as a decreased release rate of BCAA has been achieved by using larger particle sizes in the improved Aminoleban ${ }^{\circledR}$ EN formulation. 
Figures $3 \mathrm{a}$ and $\mathrm{b}$ also shows the time-course of obtained and predicted (by taste sensor) bitterness for the old and improved formulations of Aminoleban ${ }^{\circledR} \mathrm{EN}$ after $50 \mathrm{~g}$ product was suspended in $180 \mathrm{ml}$ of purified water and stored at $25^{\circ} \mathrm{C}$, respectively. The obtained and predicted bitterness data resembles so much and the taste sensor was able to predict bitterness of products. In both cases, the bitterness intensity scores of the improved Aminoleban ${ }^{\circledR}$ EN were significantly lower than those of the older product at initial phase points after sample preparation. Even though detail data not shown, a good correlation between the results of evaluation by the taste sensor and the bitterness intensity scores derived from human gustatory sensation tests at all time points $(r=0.861)$. We have previously demonstrated the usefulness of the taste sensor in predicting the bitterness of various concentrations of binary or ternary BCAA mixtures. ${ }^{8)}$ In this study, the usefulness of taste sensor was also confirmed.

We also evaluated the effect of adding five new or improved flavours to improved Aminoleban ${ }^{\circledR}$ EN. As shown in Table 1, the addition of flavours reduced the bitterness intensity of the improved Aminoleban ${ }^{\circledR}$ EN while increasing the sweetness and sourness of the product. Sweetness and sourness are fundamental tastes, and show a good correlation with the overall palatability score $(0.777$ and 0.679 , respectively). In particular, the apple, pineapple, and fruit flavours were effective in increasing the overall palatability score, while decreasing the bitterness score dramatically. For example, the bitterness of the improved Aminoleban ${ }^{\circledR}$ EN was significantly reduced by the addition of apple flavour from 1.3 to 0.7 , while the sweetness and sourness scores were increased from 0.8 to 1.3 , and from 0.2 to 2.3 , respectively.

Figure 4 shows the good correlation between the bitterness (a), sweetness (b), and sourness (c) scores as determined by human gustatory sensation tests and the corresponding bitterness scores predicted by the taste sensor. The apple, pineapple, and fruit flavours were particularly effective in decreasing the bitterness score, while contributing to the sweetness and sourness of the enteral nutrients. These findings suggest that the two basic tastes sweetness and sourness themselves decrease bitterness. ${ }^{9-11)}$

The five improved flavours contained varying percentages of citric acid: $11.7 \%$ (apple), 14.2\% (pineapple), $11.0 \%$ (fruit), less than 1\% (coffee), and 2.3\% (powdered green tea). The apple flavour also contained about $0.17 \%$ of malic acid. In our pilot study, when $700 \mathrm{mg}, 850 \mathrm{mg}$, and $660 \mathrm{mg}$ of citric acid which corresponding to same amount involved in apple, pineapple, and fruit flavours, respectively, were added to $180 \mathrm{ml}$ of BCAAs solutions $(73.28 \mathrm{~mm} \mathrm{~L}-\mathrm{Ile}, 77.65 \mathrm{~mm} \mathrm{~L}-$ Leu, and $68.37 \mathrm{~mm} \mathrm{L-Val)} \mathrm{which} \mathrm{corresponding} \mathrm{to} \mathrm{same}$ amount involved Aminoleban ${ }^{\circledR} \mathrm{EN}$, the bitterness score of their solutions were dramatically reduced from 3.3 (in the absence of citric acid) to $0.8,1.2$, and 1.3 respectively. Thus, the main organic acid in the apple, pineapple and fruit flavours, citric acid, will be a major factor in reducing the bitterness and thereby improving the overall palatability.

Neither coffee nor powdered green tea flavours reduced the bitterness of the improved formulation of Aminoleban ${ }^{\circledR}$ EN, as shown in Table 1, although, unlike powdered green tea, the coffee flavour did improve the overall palatability score considerably. There was no accounting for the taste for these flavours in individual patients. In addition, since pa-
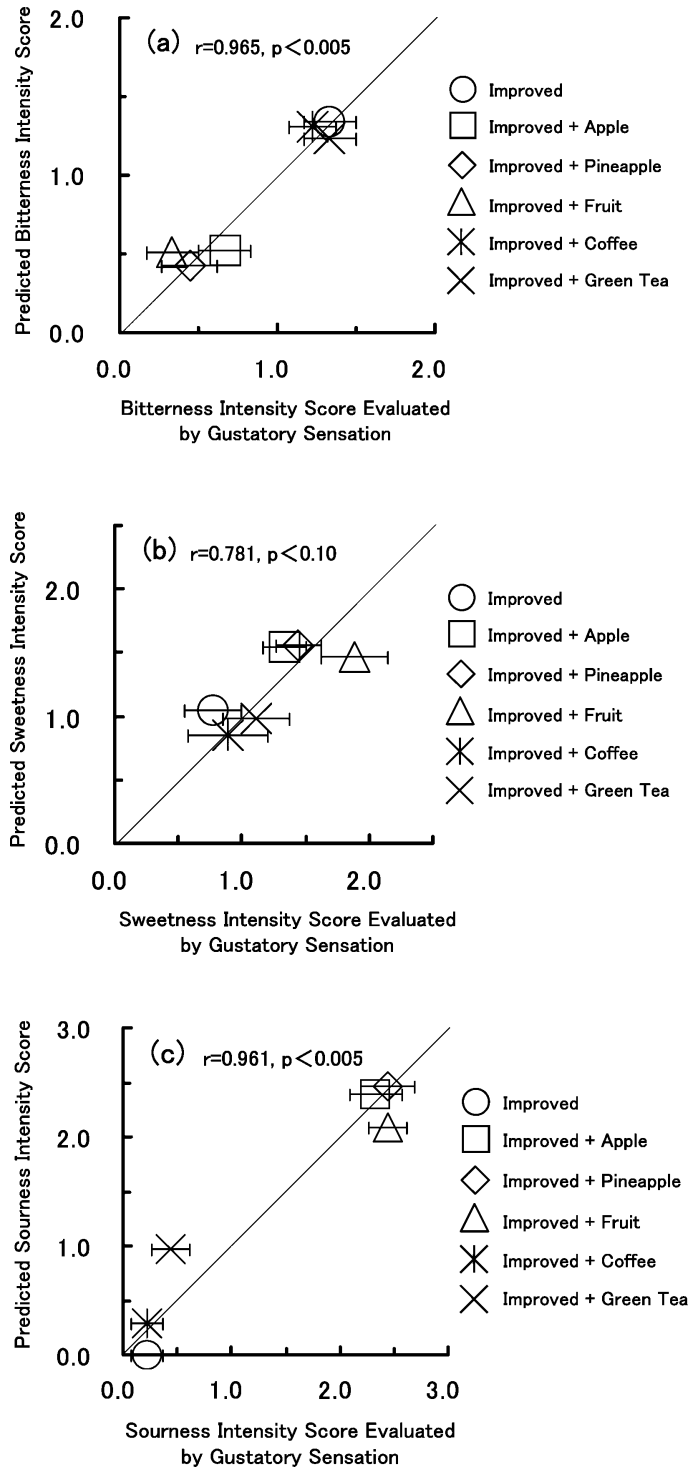

Fig. 4. The Correlation between the Bitterness (a), Sweetness (b), and Sourness (c) Intensity Scores, as Determined by Human Gustatory Sensation Tests, and the Corresponding Predicted Bitterness Intensity Scores Calculated from Taste Sensor Data

Error bars represent the mean plus or minus standard error $(n=9)$.

tients have to take these enteral nutrients for a long period, it is an advantage to have a choice of flavours. These five flavours will appeal to patients with many different taste preferences and may all be used at some stage by any patient during long-term administration.

In conclusion, the bitterness intensity of the improved Aminoleban ${ }^{\circledR}$ EN formulation was shown to be significantly lower than that of the old product, not only in human gustatory sensation tests and but also as predicted by the artificial taste sensor. This bitterness suppression is likely to be due primarily to the larger particle sizes of the BCAAs used in the improved formulation leading to slower release rates in the constituted product. Furthermore, the addition of improved flavours significantly reduced the bitterness of the improved Aminoleban ${ }^{\circledR}$ EN formulation. The sourness and sweetness of the flavours was mainly responsible for this bitterness-suppressing effect.

In a following study, we hope to clarify this bitterness sup- 
pression more quantitatively. We will also look at other enteral nutrients in an attempt to find the most critical factors in determining the overall palatability of these diets. The taste sensor will be useful for quantitative evaluation of the intensities of the fundamental taste components of various enteral nutrients.

Acknowledgements We thank Miss Yoshiko Kanemoto, Sonhi Kin, Ai Saiuchi, Emi Takeda, Emi Tokuyama, Miyuki Nakamura, Nozomi Miyatake, and Kanako Watanabe for their assistance in sensor measurement. This work was supported by a grant-in-aid from the Ministry of Education, Science, Sports, Culture and Technology of Japan (No. 15590146).

\section{References}

1) Fischer J. E., Yoshimura N., Aguirre A., James J. H., Cummings M. G., Abel R. M., Deindoerfer F., Am. J. Surg., 127, 40- 47 (1974).

2) Fischer J. E., Funovics J. M., Aguirre A., James J. H., Keane J. M., Wesdorp R. I., Yoshimura N., Westman T., Surgery, 78, 276-290
(1975).

3) Indow T., Jpn. Psychol. Res., 8, 136-150 (1966).

4) Indow T., Percept. Psychophys., 5, 347-351 (1969).

5) Katsuragi Y., Mitsui Y., Umeda T., Otsuji K., Yamasawa S., Kurihara K., Pharm. Res., 14, 720-724 (1997).

6) Uchida T., Miyanaga Y., Tanaka H, Wada K., Kurosaki S., Ohki T., Yoshida M., Matsuyama K., Chem. Pharm. Bull., 48, 1843-1845 (2000).

7) Nakamura T., Tanigake A., Miyanaga Y., Ogawa T., Akiyoshi T., Matsuyama K., Uchida T., Chem. Pharm. Bull., 50, 1589-1593 (2002).

8) Miyanaga Y., Tanigake A., Nakamura T., Kobayashi Y., Ikezaki H., Taniguchi A., Matsuyama K., Uchida T., Int. J. Pharmaceut., 248, 207-218 (2002).

9) Calvino A. M., Garcia-Medina M. R., Cometto-Muniz J. E., Rodriguez M. B., Percept. Psychophys., 54, 751-758 (1993).

10) Lawless H. T., J. Comp. Physiol. Psychol., 93, 538-547 (1979).

11) Tamura M., Mori N., Miyoshi T., Koyama S., Kohri H., Okai H., Agric. Biol. Chem., 54, 41-51 (1990). 